\title{
Everyday belonging and ageing: Place and generational change
}

\author{
Vanessa May \\ Morgan Centre for Research into Everyday Lives \\ Arthur Lewis Building \\ University of Manchester \\ Oxford Road \\ Manchester M13 9PL \\ UK \\ vanessa.may@manchester.ac.uk
}

$\&$

Stewart Muir

Australian Institute of Family Studies

Level 20, 485 La Trobe Street

Melbourne VIC 3000

Australia

stewart.muir@aifs.gov.au

\section{Author biographies}

Vanessa May is Senior Lecturer in Sociology and a member of the Morgan Centre for Research into Everyday Lives at the University of Manchester. She has conducted research on narrative identity, lone motherhood, and intergenerational relationships. Her current research focuses on belonging and on how different qualitative research methods allow researchers to shed light on different dimensions of belonging. Vanessa has published in a number of journals including Sociology, Sociological Review, International Journal of Research Methods and Narrative Inquiry, and has recently authored a book entitled Connecting Self to Society: Belonging in a Changing World (Palgrave Macmillan).

Stewart Muir is a Research Fellow at the Australian Institute of Family Studies, prior to which he worked at the Centre for Research on Socio-cultural Change (CRESC) and the Morgan Centre forResearch into Everyday Lives, both at the University of Manchester. Stewart's research has spanned indigenous cultural property in urban Australia; domestic and family traditions in the north west of England; age, belonging and neighbourhood; the role of memory and nostalgia in visions of the future; and the development and deployment of innovative and interdisciplinary qualitative research methods.

\section{Acknowledgements}

We wish to thank the other members of our project team, Jennifer Mason and James Nazroo, who played a key role in the overall design of the Inter/Generational Dynamics study. Our sincere thanks go to the participants of our Inter/generational Dynamics study who so generously contributed their time and effort. 


\section{Everyday belonging and ageing: Place and generational change}

Key words: Belonging, ageing, place, generation

\section{Abstract}

In this paper, we discuss findings from a study on intergenerational relationalities in order to examine some aspects of how people over 50 years of age experience belonging in their everyday lives. Belonging emerged not as a single unitary 'thing', but a complex intersecting of relational, cultural and sensory experiences. We explore how people, place, time and cultural context intertwined in people's sense of belonging to place. Although much previous research on belonging has largely focused on geographical movement, we found that temporal movement, at an individual level in the form of ageing and at a collective level in terms of generational change, proved to be an important layer of our participants' experiences of belonging and not belonging. Furthermore, we argue that people often come to understand and speak of temporal shifts in belonging in embodied terms, based on their sensory engagement with the world. The paper concludes by considering the consequences of this additional aspect of the experience of belonging for the study of belonging as a social and personal process, and how our findings contribute to debates around 'ageing well'.

\section{Introduction}

In this paper, we discuss findings from a study on intergenerational relationalities in order to examine some aspects of how people over 50 years of age experience belonging in their everyday lives. We bring together an exploration of ageing with a broader examination of 'belonging' as a concept and as an experience. We here understand belonging as a concept that describes the quality of individual and group attachments to the surrounding world: to people, places and 'generation'. As such, we suggest that achieving a sense of belonging entails creating a sense of identification with one's relational, material and cultural surroundings (Miller 2003), or 'of recognising - or 
misrecognising - the self in the other' (Leach 2002: 287). Yet, as we explain below, pinning down what this form of attachment or relationality might mean in day-to-day life, or what it feels like to 'belong', is often more difficult than this relatively straightforward definition suggests.

The empirical portion of this paper draws on a mixed methods study of ageing and intergenerational relationships, one part of which focused on belonging. ${ }^{1}$ We suggest that exploring trajectories of attachment to places and people, and exploring this in relation to ageing, can tell us something important about the nature of belonging. To some extent, our interest here resonates with the growing body of research on the relationship between older people's physical and social environments and their health, life satisfaction and well-being (see Andrews and Phillips 2005; Oswald et al. 2011; Buffel et al. 2013) and on older people's experiences of social and emotional isolation (Scharlach and Lehning 2013; Tomaka et al. 2006; Victor et al. 2009; Scharf and de Jong Gierveld 2008). It is clear from these that social networks and social support play a key role in 'ageing successfully', increasingly so with the very old (Bowling 2006; Aartsen and Jylhä 2011; Dykstra 2009). Despite the obvious resonances with these literature, our concern is focused on how our research participants experienced belonging rather than on social welfare, the psychological or physical effects of belonging, or policy initiatives for developing 'age friendly cities'. That said, we do hope that our paper will inform these debates by helping to build a better picture of what belonging actually means and how it is experienced, particularly in relation to changing places, social and cultural norms, and ageing bodies.

On the other hand, as we discuss in more detail in the following section, the broader belonging literature - much of which focuses on the struggles to belong (or to overcome nonbelonging), most often in the context of ethnic minority groups and migrants - tends to underplay the effect that ageing can have on a person's sense of belonging. We propose that it is therefore necessary to complement the existing literature on belonging, which tends to focus on belonging as 
a spatial or geographical experience, by explicitly focusing also on the temporal and life-course aspects of belonging.

We also argue that both sets of literatures could do more in terms of pushing the theoretical conceptualisation of belonging; indeed, even the belonging literature has been critiqued (Antonsich 2010; Skey 2011; May 2013) for not adequately theorising the nature of belonging but rather taking belonging as a given. Thus, one of our concerns lies in modes of talk about belonging and what this concept might mean in everyday life. In attempting to understand belonging in relation to our data, we argue that a person's sense of belonging is not made up of a series of independent experiences (or survey variables) that can be examined separately, but rather, the different facets of belonging are inextricably linked such that we cannot talk of one, such as belonging to place, without necessarily talking about other aspects as well, such as belonging to a socio-cultural world.

\section{Sources of belonging}

Belonging is, of course, an elusive concept. Nevertheless, a working model of belonging can be derived from its use in both the sociological and philosophical literature. Miller (2003: 218) has defined belonging in very general terms, as a sense of ease with oneself and one's surroundings and as 'the quintessential mode of being human'. Belonging can be seen as 'quintessential' because the self is inherently social and relational and requires, by definition, people to belong to (May, 2013). Calhoun (2003) suggests that belonging to a group is a universal tendency among humans and a prerequisite for personhood. Baumeister and Leary have gone as far as to argue that belonging is 'a powerful, fundamental, and extremely pervasive motivation' (1995: 497), a basic human need akin to our need for food that has a direct impact on a person's well-being (cf. Miller 2003: 218).

But people's sense of belonging is a complex experience, and can be constructed in relation to places, material objects and 'cultures' as well as people. We move through and engage with the 
look, feel, sound, smell and taste of our surroundings, and by doing so we come to know and give meaning to the world and to create a sense of self 'through place' (Tilley 1994: 15; Leach 2002: 286). In their study of belonging in Manchester, Savage, Bagnall and Longhurst (2005) found that people who felt that the area they lived in reflected who they thought they were as a person expressed a greater sense of connectedness with the area. Material objects such as clothing, photographs and mementoes also come to reflect who we are, both as a collective and as individuals (May 2013).

Our sense of self is also anchored in relation to (at times abstract) collective histories, traditions and cultures, such as 'nationhood' (for example, Skey 2011). In this paper, we examine the extent to which generation as a cultural reference group acted as a source of belonging to the people we interviewed. 'Generation' is less clearly defined than 'nation' for example - it is more diffuse and lacks clear 'markings' in terms of how it is symbolised. Our aim was to explore how our research participants talked about generation and how they used it to make sense of their own experiences. Generation is thus here seen as a category of practice rather than as a 'social fact' (White 2013; Foster 2013). In this paper, we investigate whether and how such diffuse cultural phenomena can act as a source of belonging. Based on interviews with a sub-sample of participants of the 1958 British Birth Cohort Study, Elliott (2013) found that although people are able to talk about generation, for example in terms of generational tastes in music, or of their own location in a set of kin relations as someone's child or parent, they nevertheless do not express a strong sense of generational belonging. The people who were interviewed for Elliott's paper were aged 51 at the time of interview, while our research participants were somewhat older, with an average age of 68 . Thus one of the issues we are interested in exploring is the possible impact of ageing on people's sense of generational belonging.

Although most studies on belonging have explored a single dimension only - usually either belonging to place, nationality/ethnicity or culture - there have recently been a number of calls to explore the plurality of scales of belonging and the ways in which these intersect with each other 
(May 2011; Antonsich 2010; Wood and Waite 2011). In our study, we explored belonging in relation to a wide range of topics including a person's body, their relationships, technology, culture, place and generation. This allowed us to examine the complex ways in which the different dimensions of belonging are interrelated. The existing research on experiences of belonging has also tended to focus on (minority) groups such as migrants whose sense of belonging has come under threat because of a geographical dislocation (for example, Bönisch-Brednich and Trundle 2010; Wemyss 2006). A distinctive characteristic about our sample is that most of the people we interviewed belonged to the British majority and had stayed put in the same geographical area, often for decades. This brought into relief the temporal aspects of belonging, both in terms of change over time experienced in place and culture, but also personal change in the form of the various effects of ageing. Our interview questions that asked about (inter)generational experiences no doubt also helped accentuate the many ways in which the passage of time impacts people's sense of belonging.

\section{The 'Inter/generational dynamics' project}

The 'Inter/generational dynamics' project that informs our observations on belonging (and not belonging) explored experiences of ageing and forms of intergenerational interaction with people, culture, and place. One aspect of intergenerational experience that the project touched upon in particular was the intertwining of ageing with the potential for evolving relationships to family, to age peers, to 'generation', and to place. Exploring changes to these forms of relationality allowed us to explore participants' place in, and sense of connectedness to, their world.

The overarching study involved several methodological 'facets' (Mason 2011), including analysis of data from the English Longitudinal Study of Ageing (ELSA), a linked qualitative project involving a sub-sample of 24 ELSA respondents living in or around a northern city, fieldwork in respondent local areas, participant observation at 'intergenerational' community events, interviews 
with younger relatives of ELSA participants, and focus groups (exploring engagements with digital technology) with 'older people' at community centres. Each facet was aimed at providing telling insights into how 'intergenerational dynamics' are lived and experienced by people aged 50 and over. While much research on intergenerational relationships focuses on relationships within families (for example, Mason et al. 2007; Mason and Muir 2013), we conceptualised 'intergenerational dynamics' as including relationships not only with people both inside and outside families but also with culture and place.

In this paper, we focus on the qualitative component of the study undertaken with the ELSA sub-sample. We conducted a total of 41 interviews with 24 respondents, including 38 individual interviews and three couple interviews. Fifteen of the respondents were women, nine men, with an age range of 50 to 90 and an average age of 68 . The majority $(\mathrm{N}=16)$ were living with a partner (married or co-habiting). Only two of our respondents were from a minority ethnic background. The majority ( $N=18)$ of the participants were retired at the time of the interview, though some of them continued to do volunteer work in local churches, day centres and cafes. Just under a third $(\mathrm{N}=9)$ (had) worked in a white collar professional occupation such as school teacher or engineer, while the rest (had) worked in a range of mostly blue collar occupations such as driver, cleaner, hairdresser or mechanic.

The sample was not demographically representative but rather participants were selected on the basis of residence in specific local areas so that we could explore emplaced aspects of ageing and belonging, the quality of social networks and the ways in which generational identities were generated or ascribed. The selected local areas showed either notable demographic stability or change and were chosen to provide a spread of socio-economic characteristics across the sample. The wards chosen included a largely White British affluent suburb several miles from the city centre, an inner city ward with high ethnic diversity and recent demographic changes, a city suburb with 
mixed middle income residents, and a town close to the city edge with largely White British low-tomiddle income residents.

Interactions with our interview sample included an initial in-depth interview focusing on experiences of ageing, cultural engagements, relationship to technology, and the meanings attached to 'generation' as a concept, as a historical and personal reference point, and as a measure of age and of vertical family relationships. We were interested in recording the ways in which people spoke about generations and generational identities, and investigating possible sources of generational difference, for example in relation to ageing bodies and technology. We also asked each participant to fill out an interaction diary over the course of seven days, noting down who they saw, spoke to or communicated with, and where and why these interactions took place. Participants were asked to note down every interaction they had (or as many as possible) however trivial or fleeting it may have seemed. The interaction diaries were then the starting point for a second face-to-face interview which focused on relationships with people and with places. These interaction diaries proved to be particularly valuable in helping us elicit accounts of belonging that remained somewhat elusive in the initial interviews.

In our analysis of the interviews we created a 'belonging narrative', attending to instances where belonging or non-belonging (including mentions of personal identifications with places, people or social reference groups, of feeling at home, of fitting or not fitting in) was mentioned, and explored the tenor of these accounts. Across these different cases, we then sought to identify themes, patterns, similarities and differences. One of the more obvious themes related to the complex combinations in which sources of belonging appeared in the accounts; that is, although there were a range of ways in which people did express some sense of fitting in, of satisfactory relations to people and places, they seemed not to be experienced in a unified manner and were not told to us in the form of rehearsed, coherent, narratives; rather, much of the talk about belonging in our data did not arise from direct questioning about it as a concept but from the interaction diaries 
and associated talk about people's social contacts and activities. This observation informed our subsequent analytical approach. Rather than attempting to derive a typology of belonging based on identity categories such as gender or ethnicity - for example by investigating whether men and women experience belonging differently - we aimed to preserve some of the complexity of how belonging was narrated by our respondents. Thus the aim of our analysis was not to represent belonging as a fixed object but instead to keep some of its fluidity intact, and we do so in this paper by presenting certain key patterns or 'gatherings' in the data that were brought together by our methods and amplified by our analysis (Law 2004).

Throughout the analysis, we remained mindful of the fact that we were asking people about specific topics, namely their experiences of ageing in relation to their own bodies, their relationships, culture and place. This line of investigation clearly shaped what our participants talked about, and had we raised different topics we would likely have accessed different accounts of (not) belonging. As such, and as we discuss in more detail below, this paper is not meant to be an exhaustive exploration of what belonging 'is' but rather a study of the ways in which belonging can manifest in the lives of people who are over 50 (many of whom have lived in the same area for decades). The quotes from the data are telling examples of themes that emerged from our analysis.

\section{Relational belonging to place}

We start where most studies of belonging start, that is, by examining how our respondents talked about belonging to place. Already the multidimensionality of belonging is apparent because the character of a place was commonly understood in relation to the degree of 'friendliness' of the casual encounters that took place there (cf. Buffel et al. 2013). Rodman (1992:641) has observed that belonging in place entails 'something other than a physical setting' or a 'passive target for primordial sentiments of attachment' but rather involves 'politicized, culturally relative, historically 
specific, local and multiple constructions'. Our concern here is not so much with the practical support provided by neighbours (cf. Perren et al. 2006) but rather how social relations, of all sort, contributed to a sense of attachment to geographic place (and to other people). Amongst other things, reading and talking about the interaction diaries highlighted the significance of incidental encounters to the experience of being in geographical place. Furthermore, we found that feeling comfortable in an area did not require strong social capital or close ties. A general feeling of 'friendliness' - even from strangers - was often held to be an essential part of making participants feel that an area was a good place to live and the right place for them to be (Lofland1998). Peter, a 59-year-old man living in an affluent suburban neighbourhood, said of his neighbours: 'they're all, you know, nice, friendly, helpful people'. Similarly, Grace, an 85-year-old woman living in a mixed middle income area, described her area as 'pleasant' because 'if you feel a bit er, oh you want a bit of company you've only got to walk up to the shops and plenty of company there'.

Although, as discussed above, it is most likely that a person will feel a strong sense of belonging to others who are 'like me', people can and do feel a sense of belonging to a range of different people. Victoria, a participant in her 80 s, lived alone in an area that had been largely rebuilt in the past decade and that had experienced significant demographic change, with new South Asian migrant groups moving in and many older residents leaving. However, this physical and demographic change did not shake Victoria's expressed feeling of connection to the place and the people. She still liked it there. Although Victoria had lived in the area for much of her life, it was not so much personal history that led her to regard it as 'my area' but rather the friendly microinteractions that were an essential component of her daily routines: people in the street 'let on to her' (that is, notice and acknowledge her presence):

Victoria: 'Course it's nearly all Asians and that in it now you know. But I get on well with them all. They all let on to me and that. You know, I mean, I talk to nearly all of them. 
Interviewer: Okay. So do you feel like you, do you feel like you, you feel quite connected to this place or this area?

Victoria: Yes, yes, yes. Quite happy round here. As I say I know, I know most people in the street. I don't know them by name but by sight and they all, they all let onto you and 'Are you all right?' and all this, that and the other, you know, and 'Is there anything you need?' and that, yes. It's two or three ask me that.

Something similar emerged from other participant diaries and our examination of the frequency and quality of people's social interactions. Some participants recorded an extraordinary number of ephemeral, but positive or 'friendly enough', encounters in the street and at local shops. Our analysis of these accounts suggests that such people were often those who, even if they did not always articulate a positive connection to place, were the least likely to describe the place as bad, unfriendly, dangerous, or somewhere they did not feel at home.

Such people did not necessarily engage in a great deal of what one couple described as 'neighbouring' - that is, close and regular social contact - rather their relationships with neighbours could best be characterised as (friendly) distance: "Yeah, we just talk outside, you know, over the fence or, um, we don't go in each other's homes" (Emily, aged 72). The participant diaries strongly reinforced this impression, with most showing little or no contact with neighbours over the course of the week. However, a lack of contact was not read as a lack of neighbourliness or a failure of friendly relations. What was seemingly valued was the absence of negative attributes: noisiness, bad behaviour, messiness, and so on. As Savage et al. (2005) and Blokland (2003) note, a sense of belonging does not require that the relationships between people in that community are close; a degree of anonymity can be experienced as offering space for privacy (see also Crow, 2002).

\section{Changing life situations}


Something that is less often explicitly explored in studies of belonging to place is the fact that places do not merely gain their character from relationships with other people but also from a person's life situation (though see Savage et al. 2005 and Fenster 2005 on the impact that becoming a parent can have on especially women's sense of belonging to place). Grace, a participant in her mid-80s living alone in a suburb several miles south of the city centre, described herself as having 'grown into herself' (become more insulated and withdrawn from interactions with her surrounding environment) with age; a process she associated with a certain withdrawal from and indifference to what went on outside her home. In Grace's interaction diary several days passed in which she saw no one, whilst on other days she spoke to or saw only one person. This lack of social contact could reflect the kind of social isolation and loneliness amongst older people that is of major concern to policy makers and a key topic in social gerontology (Tomaka et al. 2006; Victor et al. 2009).

As it happens, Grace presented herself as content with her life and her overall sense of belonging seemed rooted in a sense of ease with herself and a preference for solitary activities such as reading or watching television. Although Grace did indicate that she was happy enough in her local area, having lived there for decades and being on nodding terms with some local people, she also indicated that she did not have a strong attachment to the place and she avoided what she regarded as excessively frequent or lengthy contact with her neighbours. Grace mentioned, for example, a neighbour who, in an exemplary display of neighbourliness, regularly brought her the Saturday newspaper but who also, according to Grace, tended to overstay her welcome. Grace hazarded a guess that this woman must be lonely, thus reinforcing her own claim to self-reliance and preference for solitude. Thus we can see Grace's 'growing into herself' reflected in her increasing (friendly) distance to place and the people in it.

Not everyone was as happy with change as Victoria was nor as sanguine as Grace about changing relationships to place. For one of our participants, Harry (late 60s, living with his wife in a small market town with a mixed socio-economic demography) it was clear that his relationship to his 
local area was coloured by his experience of a forced retirement in his early 60 s due to ill health. Despite having been retired for five years, much of what Harry told us about his life during two interviews centred on work identity and his work ethic. He also made frequent comparisons between himself (honest, hard-working, content with his lot, brought up properly) and 'others', often younger people (whom he portrayed as lazy, expecting to get things without working for them, and badly behaved). We will return to examine this topic of perceived generational differences more closely below, but wish to note here that differences in values, attitudes and manners were also identified by the interviewees in Elliott's (2013) study as demarcating generational boundaries. Harry described these 'others' as an increasingly visible presence in his local area who were negatively impacting his sense of local belonging. Harry pinpointed the time when he retired as the time when this change became more visible. By connecting his personal circumstances and how he experienced his area, Harry rhetorically projected his own sense of disjuncture between his ideal identity (worker) and the one he had (pensioner) onto the local area. Although he noted the presence of friendly neighbours, Harry's overall sense of the area was of one of decline and it was hard to not see this as mirroring his sense of reduced ability to claim a 'moral self' due to early retirement.

Harry's account demonstrates how belonging is not merely territorial but also temporal. Some participants, like Harry, seemed to be experiencing something akin to what Fields (2011) calls 'belonging from afar': a sense of greater connection to a place where they no longer live. Many of our participants, who had lived in the same area for decades, spoke in a similar way, indicating a (nostalgic) sense of belonging from afar towards a neighbourhood lost in time. This kind of 'distanciated belonging' suggests that belonging 'is a dynamic process of negotiating past and present relationships, experiences and interests, rather than a state tethered to one's residential setting' (Fields 2011: 265).

\section{Embodied sensory belongings}


Longing for another place, in time as well as space, could also manifest in outright rejection of the present, often through a narrative of decline (for example, Savage et al. 2005; Degen 2008; Buffel et al. 2013). Monica, a 69-year-old woman living in the north of the city expressed a distinct dislike for her local area, despite having lived there for much of her life. In part, Monica's disapproval was related to a perceived decline in the physical character of the buildings and facilities:

I used to take the kids to the swimming baths or I took, well, I took [grandson1] a few weeks ago. But we've got a grotty swimming baths. [ . . ] I took him [grandson] to [name of baths] but it was disgusting. Oh, it was disgusting! Filthy, dirty, no facilities at all. So erm I didn't enjoy that. So that's gone by the by.

A further aspect of belonging to place which is often overlooked is the sensory. It is worth noting that Monica's local area had been subject to the effects of radical de-industrialisation and had high rates of unemployment, deprivation and population turnover, factors commonly associated with a reduced sense of belonging (Jørgensen 2010; Fields 2011). Although Monica's account of decline was a familiar one, and resonates with Harry's above, what is interesting about Monica's narrative of a diminished sense of belonging is its articulation in terms of her sensory engagement with the neighbourhood. When speaking, for example, of her perception of the increased presence of migrants, which she identified as one aspect of her area's decline, Monica paid particular attention to their sensory impact, mentioning the sound of foreign languages, skin colour and the look of the goods that migrants sold at the local market:

And I'd got off the bus and got to the top of the precinct and I thought what? It was, there were people sat around eating pasties and pies, kids scrawking around. People shouting and stood in groups and, and I thought to myself, and I didn't hear one English voice. So we've got lots and lots of migrants in, not that I'm, I'm not, well I don't really know, but I walk down, and honest to goodness I did not hear one English voice. [ . . . ] And the outskirts have changed as well obviously 'cause they're full of - you go up [road] and it's just you never see 
a white person. [ ... ] And in my, all the local markets, they've all changed. Because it's all full of tat. It's I, I'm sounding racist here, but I'm not. I'm just saying it's now full of erm Asians and whatever selling their wares, but they're all the same, you know what I mean? [ . .. ] And it's all the same tat.

Monica also pointed to social class as a reason for why she hates her area 'with a vengeance', describing the local residents in ways that exemplify stereotypical notions of 'disrespectable' working-class people (Skeggs 1997; Tyler 2008). Once again, she notes the sensory impact that living amongst such people has had for her:

I don't know, I just, I don't like the people. No, I can't say I don't like the people, that's wrong. I, I don't like the, well, yeah, the people. No, not knowing them, do you know what I mean, just walking .... through them so I very rarely go into [town], erm, because I don't like the people. They're scroats, always faggin' it, oh, screaming at the children, F-ing and, no, I don't like it. It's a horrible place, [town].

Fields (2011: 258-9) notes how deprived areas that are 'under-resourced and ill-served' can be experienced by residents as 'forgotten and unimportant' places that they therefore wish to distance themselves from. Certainly, in her accounts of her town, Monica repeatedly engaged in a 'strategy of non-belonging', as Fields calls it, by signalling her difference from other residents and her personal transcendence of the generally run-down area. It is interesting that she does so through examples of her embodied sensory experience of her area as 'polluted' by dirt and 'strange' or unwelcome sounds, sights and smells (cf. Degen 2008).

The sensory effect of place evident in Monica's account was not always only a consequence of external physical changes in the surroundings. Embodied experiences of ageing were also highly significant, both in themselves and in relation to place. Certainly physical fitness and health was of great concern to some of our respondents, with several suffering from ill health, and many noted 
the impact that this had had on their ability to act in, engage with and be in the world, with some respondents describing shrinking zones of comfortable movement, a general sense of dis-ease and/or a perceived lack of safety (cf. Buffel et al. 2013). Bridget, a 67-year-old woman living with her partner in a suburban estate of moderately sized bungalows, described a distinct temporal and bodily dis-ease with many aspects of the world, often describing herself as not at home in the present. She spoke, for example, of her inability to find clothes that fit and of a bodily discomfort in cities, which she described as 'young people's places' with too much buzz and noise. This was, in some respects, a generational perception of place but also part of an account of physical discomfort. Bridget presented herself as someone uncomfortable with her surroundings and in her body, as the victim of an on-going series of physical ailments and illnesses that limited what she could do.

\section{Belonging to generation}

Clearly then, belonging hinges on a range of interconnected relational and embodied experiences; in our data these experiences were also often marked by the passage of time. Time was also a salient issue when our participants spoke of their affinity with popular culture, current modes of speech, dress, behaviour and values. What we explore below is the extent to which generation as a cultural reference group ('people of my generation') can act as a source of belonging and of collective understandings of what it means to be 'us'. In particular, we are interested in the impact that ageing might have on any sense of generational belonging (cf. Elliott 2013).

When first interviewed, Louise, an 80-year-old woman living alone in a relatively affluent suburb, was in the process of moving from the ex-council house she had lived in for over fifty years to an assisted-living flat. This move was not prompted by physical need but rather by Louise's perception of the area's transformed generational identity relative to herself; that is, her age peers had mostly died or left. In describing this change, Louise did not use the same tropes of decline as did Harry or Monica: she noted that the place itself was largely the same and that she maintained 
friendly relations with her newer neighbours. Yet, she felt that such relationships were relatively shallow because they were not built on common experience; she wanted the company of people her own age:

Interviewer: And you're selling the house now, why is that?

Louise: Well everybody's, dying off shall I say that. The people of my generation have either died or they've moved elsewhere. Nothing at all wrong with the young ones but there's not common ground as there used to be, so I'm hoping to go into a flat where there'll be people of my generation, some sort of more alert than others, but there will be a continuity of company and socialising and so on.

Again, we can note here the interconnectedness of different aspects of belonging. Talk of 'generation' was often explicitly about 'people like me' with similar experiences and outlook on life. What is more, this experience of being part of a particular 'generation' (or not) coloured particularly the older respondents' relations to and in place:

Louise: But, unless I go out, there's not a great deal of communication with anybody. It's just sort of casual conversations, how are you and it's a nice day and this, that and the other. The lads that work in the shop there, late teens, 20s, I ask them about what they're doing at college and uni and that sort of thing and we get the conversation there, but it is just fleeting, it's not in-depth. So it's mostly when I get out, to go out that I get conversations and things to do. $[\ldots]$ I don't want to be talking all the time, but it's nice to have a bit of in-depth conversation, you know to think, to talk about what we think is happening in the world, and well things in general.

Some accounts of changing attachments to people and place also drew on narratives of an ever younger 'society', of older generations alienated by trends in fashion, music and consumer spending (evident for example in Bridget's account of cities). This apparent alienation from modernity was not 
always perceived as entirely bad: many of the interviewees claimed to be glad they were not young in a world that had become harsher, faster, and with increased pressures to obtain material goods. Such distancing functioned, in part, as a critique of contemporary society and signalled participants' lack of responsibility for the apparent problems of contemporary life. However, such critiques also suggested an identification with generational position. This was evident in some participants not only distancing themselves from the subsequent generation but also from the one previous to theirs; a recurring theme was the sense of the moral and material compass having hit an optimal point with their generation. This was a moral claim but it also segued into accounts of comfort with people of their own age that echoed Mannheim's (1952) definition of generation as people who have shared the same experiences at the same stage in the lifecycle:

Interviewer: In what way do you feel that you are part of a generation?

Louise: Well I s'(pause), mainly I suppose because of the experiences that we've shared. You can relate to various things like we were in the war and, er, after the war and having kids at the same time, that sort of thing, it's mostly experiences you've shared, I think, as much as anything else. [ . . . ] So it is mainly in, in things that we've shared years ago, I think, that I feel in touch with my own generation.

That is, although some of our participants spoke about a sense that the world was changing around them this did not necessarily translate into a sense of non-belonging because they still had a niche in contemporary life in which they belonged, at least for as long as there were enough people of a similar age who viewed contemporary life and remembered the past in a similar way. In the case of our older respondents aged 80 and over, this niche was slowly diminishing. We argue that it is perhaps in this situation, when one's generation is slowly dying out, that a person might become acutely aware of their own generational identity, and to keenly feel a sense of generational belonging. For some of our interviewees, this was turning into a form of 'belonging from afar' (cf. Fields 2011). Perhaps generational belonging, which Elliott (2013) did not detect very strongly 
among respondents aged 51 , is something that remains largely unnoticed until one's generation begins to thin out and disappear.

\section{Discussion}

This paper has explored how people over 50 talk about their experiences of belonging. By bringing two literatures, on ageing and on belonging, into dialogue with each other, we have been able to make important contributions to both by highlighting the temporal and sensory aspects of belonging as they are experienced by people with ageing bodies who, as they grow older, find themselves members of diminishing generational cohorts. One of the first things we found was that belonging seemed to be experienced in a fragmented manner, and was consequently not expressed in terms of a 'whole', but rather in more complex ways. Belonging is thus one among many research objects 'that slip and slide, or appear and disappear, change shape or don't have much form at all' (Law 2004: 2) and is therefore difficult to 'capture'. We argue that trying to find a singular 'belonging' that can be known with absolute certainty or creating a typology of how different people experience belonging would create a misleadingly coherent and static picture of belonging as it is lived. Instead, we have explored varying manifestations of belonging, seeing these as fluid facets of a whole that can never fully be captured, with the knowledge that these have to a degree been shaped by our own methods (the questions we have asked and how we have asked them), and that there are sure to be more out there.

Our participants spoke of belonging in relation to a variety of sources, including people, cultures and places. We found that these sources of belonging can exist almost independently of one another in some instances whilst in others there is a considerable degree of overlap, often to the point of inextricability. For some, experience of place is coloured by the relationships they have there with family, friends, acquaintances and strangers. In other cases, some forms of belonging 
cancel others out - for example an acute sense of living amongst people who are 'different' can overshadow a physical ease with a place that one has grown to know over the years. For some people, relationships are the most important source of belonging, for others it can be sensory belonging, for yet others a sense of cultural belonging. Consequently, a person's sense of belonging can never be predicted, nor can one easily determine in advance the 'variables' that could be used to measure it.

Whereas much of the research on belonging has focused on geographical displacement as a threat to belonging, by exploring belonging through the lens of ageing and generation we have been able to shed light on the temporal aspects of belonging as well. We found, similarly to other studies (for example, Savage et al. 2005; Degen 2008; Buffel et al. 2013), that as localities change over time, residents' sense of belonging to their area of residence can come under threat. While some seem to be able to re-create their sense of belonging for example through a re-learned bodily awareness of the place, others experience a more permanent sense of dislocation. But aspects of change that are often left unexamined in such studies are the effects that ageing as an individual experience and the passage of time as a collective one can have on a person's sense of belonging to place. In other words, we argue that a sense of dislocation need not always be geographical, but can rather also be experienced as a temporal displacement. Changes in life situations, such as unemployment or worsening health, can have a profound impact on a person's sense of belonging. Furthermore, we propose that places can be experienced as 'generationed', that is, as reflecting the values and lifestyles of certain generations over others. Partly this is to do with who lives in an area, but also with broader cultural shifts such that for example city centres are experienced as uncomfortable spaces that cater to the interests and consumption patterns of younger generations.

It seems that as people age (and become ostensibly part of an 'older generation') they can experience a lessening of belonging to the broader social context where 'younger generations' now have a crucial role to play, while at the same time their sense of belonging to a 'vanishing' 
generation can become heightened. As such, ageing potentially moves people out of a secure place in the world in an analogous way to migration (but with certain key differences, perhaps most notably in its partial but gradually growing impact). While most of our respondents talked of a general sense of commonality with people of the same age, this seemed to become increasingly acute the older they were. We suggest that people can come to more clearly notice their generational belonging when their cohort begins to die away and increasingly, their interactions are with younger people, who even though friendly, are felt to embody a slightly different view of the world. This can feel akin to living in a country that is simultaneously foreign and familiar, creating for some a nostalgic sense of belonging from afar to a time when they were deeply embedded in their 'own' generation. We would therefore argue that the debates over whether or not people possess a generational consciousness seem to have overlooked that, perhaps rather ironically, generational belonging can be a temporal issue tied to a person's stage in the life-course.

We have also highlighted the embodied nature of experiences of (not) belonging. Many of the changes listed above are partly experienced as changes in the look, feel, smell and sound of the surrounding world, or as a diminished bodily capacity to act and be within the world. We therefore urge future studies on 'ageing well' and the social exclusion/inclusion of older people to remain attuned not only to the spatial and relational dimensions of belonging, but also the temporal (as both collectively and individually experienced) and sensory. Furthermore, it is important not to try to pre-determine what belonging consists of, but rather explore the ways in which the different dimensions of belonging - relational, cultural, temporal and sensory - interact with each other to contribute to a person's overall sense of (not) belonging, thus influencing that person's capacity to act in their surroundings.

\section{References}


Aartsen, M. and Jylhä, M. (2011) 'Onset of loneliness in older adults: results of a 28 year prospective study', European Journal of Ageing, Vol. 8, Issue 1, p. 31-38.

Andrews, G.J. and Phillips, D.R. (eds) (2005) Ageing and Place: Perspectives, Policy, Practice, London: Routledge.

Antonsich, M. (2010) 'Searching for belonging: An analytical framework', Geography

Compass, Vol. 4 Issue 6, p. 644-659.

Baumeister, R. F. and Leary, M. R. (1995) 'The need to belong: Desire for interpersonal attachments as a fundamental human motivation', Psychological Bulletin, Vol. 117, Issue 3, p. 497-529.

Beilin, R. (2005) 'Photo-elicitation and the agricultural landscape: 'Seeing' and 'telling' about farming, community and place', Visual Studies, Vol. 20, Issue 1, p. 56-68.

Blokland, T. (2003) Urban Bonds: Social Relationships in an Inner City Neighbourhood (trans. Lee K. Mitzman), Cambridge: Polity.

Bowling, A. (2006) 'Lay perceptions of successful ageing: Findings from a national survey of middle aged and older adults in Britain', European Journal of Ageing, Vol. 3, Issue 3, p. 123-136.

Buffel, T., Phillipson, C. and Scharf, T. (2013) 'Experiences of neighbourhood exclusion and inclusion among older people living in deprived innercity areas in Belgium and England', Ageing and Society, Vol. 33, Issue 1, p. 89-109.

Bönisch-Brednich, B. and Trundle, C. (eds). (2010) Local Lives: Migration and the Politics of Place, Farnham: Ashgate.

Calhoun, C. (2003) '“Belonging” in the cosmopolitan imaginary', Ethnicities, Vol. 3, Issue 4, p. 531553.

Crow, G. (2002) 'Neither busybodies nor nobodies: Managing proximity and distance in neighbourly relations', Sociology, Vol. 36, Issue 1, p. 127-145. 
Degen, M.M. (2008) Sensing Cities: Regenerating Public Life in Barcelona and Manchester, London: Routledge.

Dykstra, P. A. (2009) 'Older adult loneliness: myths and realities', European Journal of Ageing, Vol. 6, Issue 2, p. 91-100.

Elliott, J. (2013) 'Talkin' “bout my generation”: Perceptions of generational belonging among the 1958 cohort', Sociological Research Online, Vol. 18, Issue 4, <http://www.socresonline.org.uk/18/4/13.html>.

Fenster, T. (2005) 'The right to the gendered city: Different formations of belonging in everyday life', Journal of Gender Studies, Vol. 14, Issue 3, p. 217-231.

Fields, D. (2011) 'Emotional refuge? Dynamics of place and belonging among formerly homeless individuals with mental illness', Emotion, Space and Society, Vol. 4, Issue 4, p. 258-267.

Foster, K. (2013) 'Generation and discourse in working life stories', British Journal of Sociology, Vol. 64, Issue 2, p. 195-215.

Jørgensen, A. (2010) 'The sense of belonging in new urban zones of transition', Current Sociology, Vol. 58, Issue 1, 3-23.

Law, J. (2004) After Method: Mess in Social Science, London: Routledge.

Leach, N. (2002) 'Belonging: Towards a theory of identification with space' in Hillier, J. \& Rooksby, E. (Eds.) Habitus: A Sense of Place, Aldershot: Ashgate.

Lofland, L. H. (1998) The Public Realm: Exploring the City's Quintessential Social Territory, New Brunswick, NJ: Aldine Transaction.

Mannheim, K. (1952) Essays on the Sociology of Knowledge, London: Routledge. 
Mason, J. (2011) 'Facet methodology: The case for an inventive research orientation', Methodological Innovations Online, Vol. 6, Issue 3, p. 75-92.

Mason, J., May, V. \& Clarke, L. (2007) 'Ambivalence and the paradoxes of grandparenting', Sociological Review, Vol. 55, Issue 4, p. 687-706.

Mason, J. \& Muir, S. (2013) 'Conjuring up traditions: Atmospheres, eras and family Christmases', Sociological Review, Vol. 61, Issue 3, p. 607-662.

May, V. (2011) 'Self, belonging and social change', Sociology, Vol. 45, Issue 3, p. 1-16.

May, V. (2013) Connecting Self to Society: Belonging in a Changing World, Basingstoke: Palgrave Macmillan.

Miller, L. (2003) 'Belonging to country - A philosophical anthropology', Journal of Australian Studies, Vol. 27, Issue 76, p. 215-223.

Oswald, F., Jopp, D., Rott, C. and Wahl, H.-W. (2011) 'Is aging in place a resource for or risk to life satisfaction?', The Gerontologist, Vol. 51, Issue 2, p. 238-250.

Perren, K., Arber, S. and Davidson, K. (2004) 'Neighbouring in later life: The influence of socioeconomic resources, gender and household composition on neighbourly relationships', Sociology, Vol. 38, Issue 5, 965-984.

Rodman, M. (1992) 'Empowering place: Multilocality and multivocality', American Anthropologist, Vol. 94, Issue 3, p. 640-656.

Savage, M., Bagnall, G. and Longhurst, B. (2005) Globalization and Belonging: The Suburbanization of Identity, London: Sage.

Scharf, T. and De Jong Gierveld, J. (2008) 'Loneliness in urban neighbourhoods: An Anglo-Dutch comparison', European Journal of Ageing, Vol. 5, Issue 2, p. 103-115. 
Scharlach, A. E. and Lehning, A. J. (2013) 'Ageing-friendly communities and social inclusion in the United States of America', Ageing and Society, Vol. 33, Issue 1, p. 110-136.

Skeggs, B. (1997) Formations of Class and Gender: Becoming Respectable, London: Sage.

Skey, M. (2011) National Belonging and Everyday Life: The Significance of Nationhood in an Uncertain World, Basingstoke: Palgrave Macmillan.

Tilley, C. (1994) A Phenomenology of Landscape: Places, Paths and Monuments, Oxford: Berg.

Tomaka, J., Thompson, S. and Palacios, R. (2006) 'The relation of social isolation, loneliness, and social support to disease outcomes among the elderly', Journal of Aging and Health, Vol. 18, Issue 3, p. 359-384.

Tyler, I. (2008) '“Chav mum, chav scum": Class disgust in contemporary Britain', Feminist Media Studies, Vol. 8, Issue 1, p. 17-34.

Victor, C., Scambler, S. and Bond, J. (2009) The Social World of Older People: Understanding Loneliness and Social Isolation in Later Life, Maidenhead: Open University Press.

Wemyss, G. (2006) 'The power to tolerate: Contests over Britishness and belonging in East London', Patterns of Prejudice, 40(3): 215-236.

White, J. (2013) 'Thinking generations', British Journal of Sociology, Vol. 64, Issue 2, p. 216-247. Wood, N. and Waite, L. (2011) 'Editorial: Scales of belonging', Emotion, Space and Society, Vol. 4, Issue 4, p. 201-202. 


\footnotetext{
${ }^{1}$ The Inter/generational Dynamics project was a component of the Realities (Real Life Methods for Researching Relationalities) programme, part of the ESRC National Centre for Research Methods, grant reference RES-576-25-0022. The research team comprised Jennifer Mason, Vanessa May, Stewart Muir and James Nazroo at the University of Manchester. The study was granted ethical approval by the University of Manchester and adheres to the ethical guidelines of the British Sociological Association.
} 